\title{
ASSESSMENT OF SEISMIC PERFORMANCE CHARACTERISTICS OF REINFORCED CONCRETE BUILDINGS CONSTRUCTED BETWEEN 1936 AND 1975
}

\author{
D. R. Brunsdon ${ }^{1}$ and M. J. N. Priestley ${ }^{2}$
}

\section{SYNOPSIS}

\begin{abstract}
This paper describes the results of an investigation into the expected seismic performance of reinforced concrete buildings constructed between 1936 and 1975. Typical design and construction features of these buildings are reviewed, including a chronological comparison of post-1935 seismic design levels. Two reinforced concrete frame buildings constructed in the 1950 s were the subject of inelastic analysis, and it is found that member shear and poor joint performance tended to govern the ultimate response. An analysis procedure for evaluating the seismic performance characteristics of reinforced concrete frame elements is proposed. Case studies illustrate this method, one of which highlights the adverse influence of highly eccentric building layout.
\end{abstract}

\section{INTRODUCTION}

In recent years considerable attention has been given to improving the seismic resistance of existing unreinforced masonry and concrete buildings that were designed before December 1935. This date marks the publication of NZSS $95^{\circ}$, the first code in New Zealand to require all buildings to be subject to seismic design requirements. However, inevitable shortcomings of both NZSS 95 and its successor, NZSS $1900^{2}$ (first published in 1964) suggest that buildings constructed between 1936 and 1975 may possess insufficient strength and ductility in comparison with structures designed to the current loadings code, NZS 4203:1976 and associated materials codes.

This study was undertaken with the aim of investigating design characteristics of buildings constructed during this period, and to thereby attempt to predict the likely performance of such structures if subjected to a severe earthquake.

\section{Seismic Design Requirements}

The principles underlying the seismic design provisions of NZSS 95 are the same as those which provide the basis for the subsequent standard NZSS 1900 and NZS 4203. These include the desirability of symmetry and integrity of structural components, the use of an equivalent static force method of analysis to determine horizontal design forces and the use of stiffness analysis methods for distributing the design forces. The key difference between early and current codes is that structures designed according to NZSS 95 were assumed to remain elastic, with working stress methods being used for all materials. This was also the case with NZSS 1900, although the concept of ductility was introduced in general terms.

BULLETIN OF THE NEW ZEALAND NATIONAL SOCIETY FOR EARTHQUAKE ENGINEERING, VOL. 17, NO. 3, SEPTEMBER 1984
It is of interest to compare the magnitudes of the seismic design coefficients specified by NZSS 95, NZSS 1900 and NZS 4203, for short period structures $(\mathrm{T}<0.45 \mathrm{sec})$. This category encompasses the majority of buildings constructed during the period of interest, for it includes buildings in which either walls or low-rise frames predominate.

Examination of the raw coefficients specified by the codes does not, however, give a fair comparison, because of two factors. First, since NZSS 95 and NZSS 1900 stipulate elastic design to specified stress limits, conversion to equivalent ultimate strength coefficients must be made before comparison with NZS 4203 levels. Second, NZS 4203 recognises ductility capacity of different structural systems detailed. to current material codes, by specifying structural type factors (S) and material factors (M). The level of ductility, $\mu$ required of a structure is implied by the

$$
\mu=\frac{4}{S M}
$$

In the earlier codes, levels of ductility demand were not stated, nor implied, and material codes did not include detailing requirements to provide ductility. Thus, though a comparison of seismic design coefficients is easy to make, it bears little resemblance to the relative intensity of ground shaking able to be sustained by buildings designed to the different codes. In order to provide some insight

1 Structural Engineer, Smith Levchars Ltd, Wellinc:ten.

2 Reader in Civil Engineering, University of Canterbury, Christchurch, New Zealand. expression 
into this aspect, Figure 1 compares equivalent ultimate strength base-shear coefficients, multiplied by the design ductility level. By the equal displacement principle, this can be considered equivalent to the elastic response level of a structure with the same period, but unlimited strength. The appropriate coefficient for structures designed to NZS 4203 (including the draft amendment A3) is thus

$$
\mathrm{C}_{\mathrm{eu}}=\mathrm{CSMR} \mu
$$

Putting the risk factor $\mathrm{R}=1$ for convenience of comparison, and noting from equation 1 that $S M \mu=4$, then

$$
\mathrm{C}_{\mathrm{eu}}=4 \mathrm{C}
$$

regardless of structural form.

For structures designed to the earlier code, the level of available ductility is uncertain, and will depend on structural form, failure mode, material, and detailing. Coefficients plotted in Figure 1 have been converted to equivalent ultimate values by the equation

$$
\mathrm{C}_{\text {eu }}=\phi\left(\frac{100}{\mathrm{P}}\right) \mathrm{C} \mu^{\prime}
$$

where $C$ is the specified coefficient, and $p$ is the allowable material stress [typically reinforcement tension stress] including overstress allowance for seismic load expressed as a percentage of yield stress, allowed in the appropriate materials code of the day. Note that to provide a fair comparison the current strength reduction factor, $\phi$, must be included in equation 4. Assuming a reinforced concrete structure and a beam hinging mechanism, the appropriate value is $\phi=0.9$.

A range of possible ductility capacities $\left(\mu^{\prime}\right)$ is shown in Figure 1 for early structures, although it is considered that $\mu^{\prime}=2$ is the most appropriate for comparison purposes, due to the likely influence of poor shear capacity and inadequate confinement. This diagram includes a transition zone linking values applicable in NZSS 1900 in 1970 to those of NZS 4203 in 1976 due to the gradual change from working stress to ultimate strength design methods during this period.

It can be seen that buildings designed to NZSS 1900 with a ductility capacity of $\mu^{\prime}=2$ are capable of withstanding approximately 60 percent of current levels, irrespective of location. Similar structures designed to NZSS 95 and located in seismic zone $A$ are, however, capable of withstanding only 40 percent of the current design seismic level.

This graph can also be used to illustrate the 'moderate' earthquake level used for strengthening buildings, and defined by section 624 of the Local Government Act of 1979 to be one half of the NZSS 1900 lateral force levels. This applies primarily to pre-1936 unreinforced masonry and concrete structures, but is of interest due to its contentious nature. For the $\mu^{\prime}=1$ case which is appropriate for non-ductile masonry, Figure 1 shows that this legislative moderate earthquake corresponds to approximately 15 percent of present code levels. Similarly, the commonly adopted upgrading lateral force level of two-thirds of the level specified by NZSS 1900 corresponds to 20 percent of NZS 4203 levels.

\section{Ductile Detailing}

The effect of the lack of ductile detailing is a significant unknown in assessing the behaviour of early reinforced concrete structures. The need for adequate detailing measures was not appreciated by early designers, nor required by codes and this can be illustrated by considering the arrangement of transverse reinforcement in critical regions of frame members. The spacing of stirrups in potential plastic hinge regions of beams and end-zones of columns were governed by shear requirements only, with no consideration given to providing confinement for the core concrete, or compression reinforcement, of these members. The stirrup spacings in frames of early design are typically greater than six times the diameter of the main reinforcing bars, which implies that the core concrete is effectively unconfined. Anchorage of transverse reinforcement was also typically inadequate by today's standards.

However, despite this apparent shortcoming, these members may still theoretically achieve relatively high section curvature ductilities. Considering the beam of a typical mid-1950s frame represented in detail B of Figure 3 as an example, calculations indicate that a section curvature ductility of approximately 10 can be expected from this member. This result is based on the assumption of an unconfined section ( stirrup spacing $=6.8 \mathrm{~d}_{\mathrm{b}}$ ), with a maximum concrete compression strain of $\varepsilon_{C}=0.004$.

A potentially more critical area with respect to ductile detailing is the beamcolumn joint core. The joints of frames constructed up until the early 1960s typically feature no horizontal or vertical joint reinforcement, as illustrated in Figure 2a. This means that joint shear resistance comes only from the core concrete itself, although the intermediate vertical column bars may provide some vertical shear capacity. Also of concern are the methods of beam bar anchorage commonly employed in exterior joints, some of which are illustrated in Figure $2 \mathrm{~b}$. Plain bar was used for flexural reinforcement, and slippage through the joint core could be expected at an early stage of ductile response.

\section{Materials Strengths}

Recent investigations by the Ministry of Works and Development have indicated that actual values of $f^{\prime}$ and $f_{y}$ in existing stnctures may be considerably higher than originally specified $4,5,6)$. Results of tests on concrete core and reinforcing steel samples taken from three road bridges constructed between 1933 and 1940 


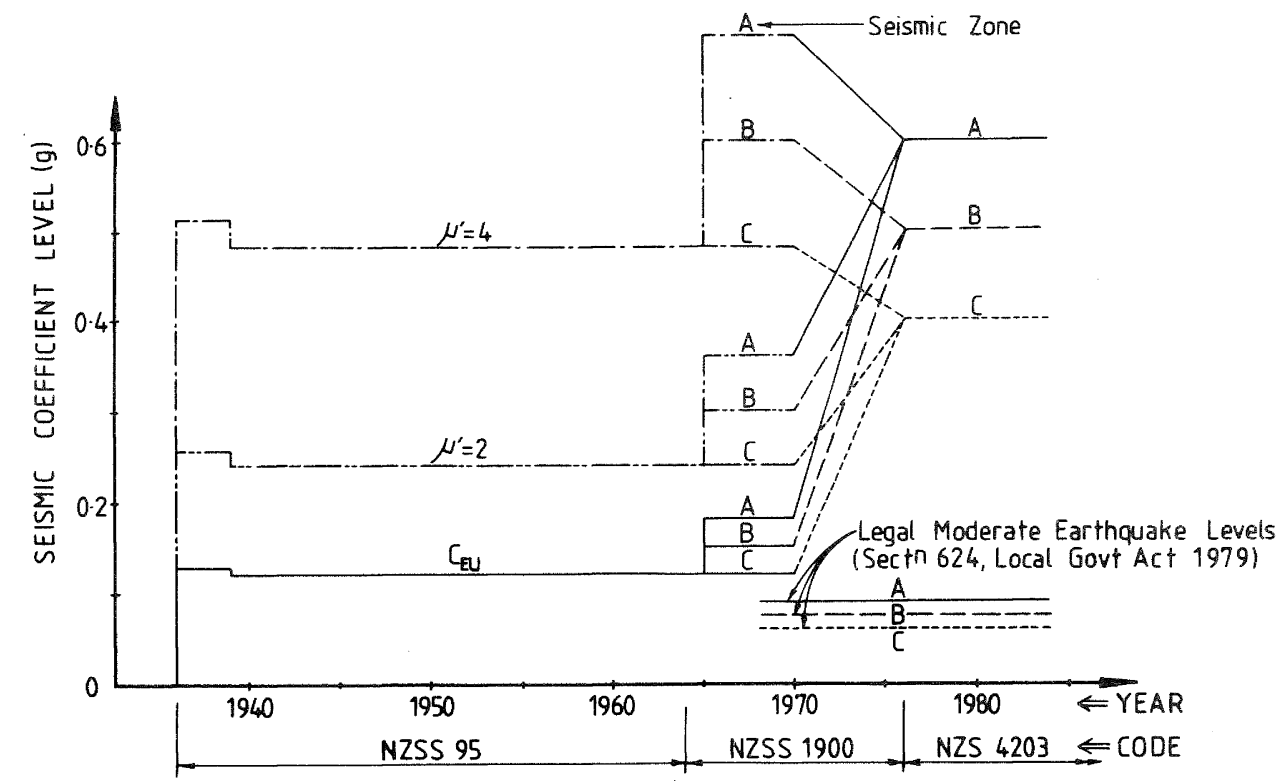

Figure 1

Chronological Code Lateral Load Comparison - Short Period Reinforced Concrete Structures (Converted to equivalent ultimate load elastic response level)

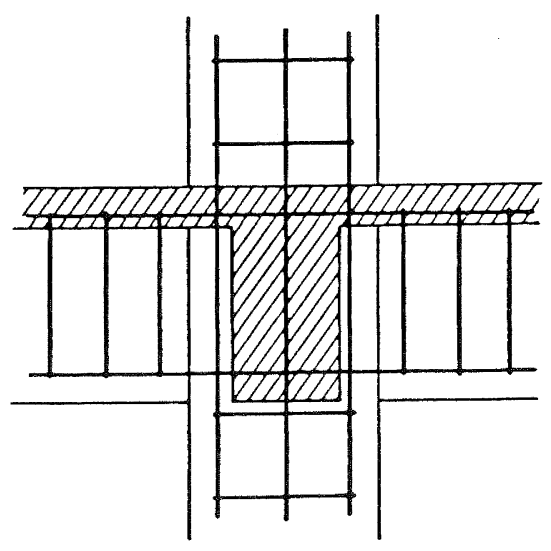

(a) Interior Joint
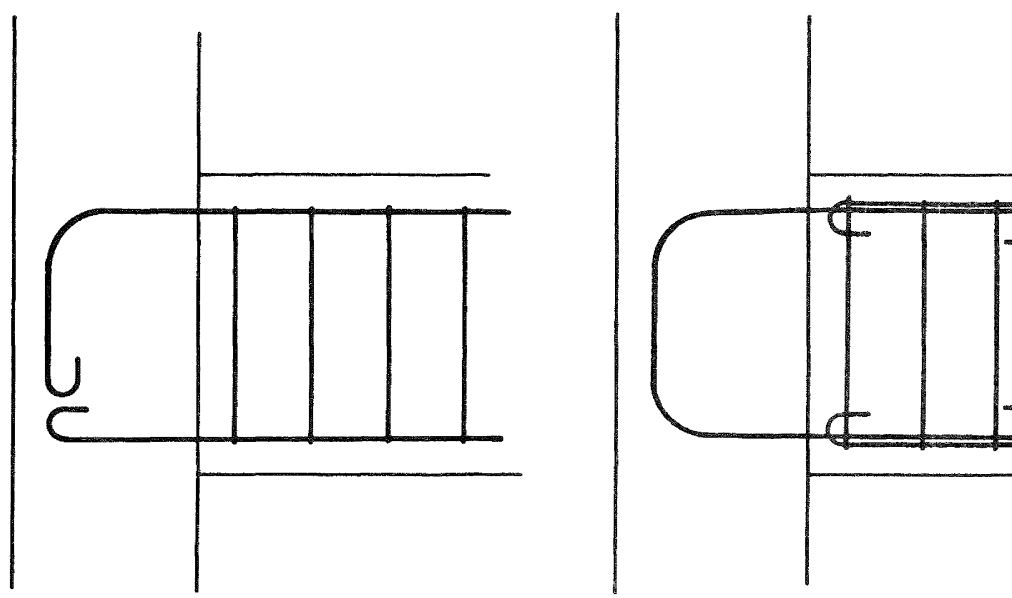
prior to demolition are shown in Table 1. In particular, it will be noted that actual concrete strengths at 50 years exceed the specified 28 day strengths by 200 percent on average.

A comparative analysis was carried out to determine the influence of enhanced concrete strength on member capacities, using a f' value of 1.5 times that originally specified. The possible increase in the yield stress of reinforcing steel was not quantitatively considered, as any increase does not appear to be either as predictable or as significant as for concrete. Results of this comparison are discussed under the relevant member strength headings in the following section.

\section{EVALUATION OF MEMBER CAPACITIES}

This section looks at the use of current design methods to evaluate the strengths of individual members of frames constructed during the period of interest, with particular emphasis on the applicabili,ty of the seismic provisions of NZS $3101(7)$. Typical member section details of two frames constructed in the mid-1950s are shown in Figures 3 and 4 .

\section{Beam Flexure}

Ultimate strength methods can be applied without difficulty to determine the flexural strength of beams. Reinforcing bars were almost universaliy Grade 275 until the late $1960 \mathrm{~s}$, and all bars were typically non-deformed until the early 1960 s. This latter point cannot be taken into direct account when determining flexural capacities, but the likelihood of poor bond performance resulting in degradation of moment capacity in plastic hinge regions as a result of cyclic inelastic action must be accepted.

Using a concrete strength 50 percent greater than originally specified as described in the previous section produced increases in the flexural capacity of less than 5 percent. The increase was much less significant for the positive moment case, for the increase in the internal lever arm is less pronounced with the shallow compression block of the ' $T$ ' flange.

\section{Beam Shear}

The shear design provisions fontained in Chapter Seven of NZS 3101 (f) define two levels of concrete shear contribution, $\mathrm{v}_{\mathrm{C}^{\prime}}$ is given by

$$
v_{c}=v_{b}=\left(0.07+10 p_{w}\right) \sqrt{f_{C}^{\prime}} \text { Code }(E q 7-3)
$$

and

$$
v_{i}=v_{c}+v_{s}
$$

(Clause $7 \cdot 3 \cdot 6 \cdot 2)$

is referred to as the ideal non-ductile beam shear capacity.
The ductile provisions are aimed at estimating the dependable shear resistance at maximum expected ductility. For a ductile reinforced concrete frame, member ductilities of up to $\mu=8$ can be expected. However, the shear capacity is likely to degrade gradually from the non-ductile value to the ductile value as ductility increases.

Since ductility capacity of structures designed to the earlier codes is likely to be limited, the non-ductile shear capacity appears to be the more relevant value when seeking to initially determine the ultimate response of a frame structure. This point is discussed further later on in this arficle, and at greater length elsewhere ${ }^{(8)}$.

Enhanced concrete strength clearly does not affect predicted shear strength in potential plastic hinge regions. Nonductile shear strength of typical examples was found to increase by about 7 percent for a 50 percent increase of $f^{\prime}$. Though this is greater than the flexural enhancements, it is still rather insignificant.

\section{Column Flexure}

The flexural strength of existing columns can be determined using ultimate strength methods, bearing in mind the comments made earlier for beam flexural capacities.

The principal difficulty in calculating column flexural strengths relates to the estimation of the level of axial load that is likely to be acting. For design, the greatest tension (least compression) and maximum compression axial loads are used, and to this end, two different axial load cases are generally employed. They can be expressed in capacity design terms as

$$
\mathrm{P}_{\mathrm{e}}=\mathrm{P}_{\mathrm{D}}+\mathrm{P}_{\mathrm{LR}}+\mathrm{P}_{\text {eq }}^{\circ}
$$

and

$$
P_{e}=0.9 P_{D}-P_{e q}^{\circ}
$$

in which $\mathrm{P}^{\circ}=$ the extreme earthquake induced axialq force. The use of two separate cases in analysis is undesirable, for this complicates the assessment of the frame as a whole. Previous resarch by Jury (9), in which four frames of varying geometries were investigated using inelastic time-history techniques, illustrated that the minimum compression values given by Equation (6) above were never approached under either the El Centro or Parkfield excitations. For these reasons, a single load case of the form

$$
P_{e}=P_{D}+P_{L R} \pm P_{e q}^{\circ}
$$

is suggested for use in the analysis of existing frame structures.

A further problem involves determining $\mathrm{P}^{\circ}$ ' for initially the appropriate level of lateral load resisted by the frame is unknown. To circumvent this problem, an elastic frame analysis assuming a fully ductile response (ie $S=M=0.8$ ) can be 


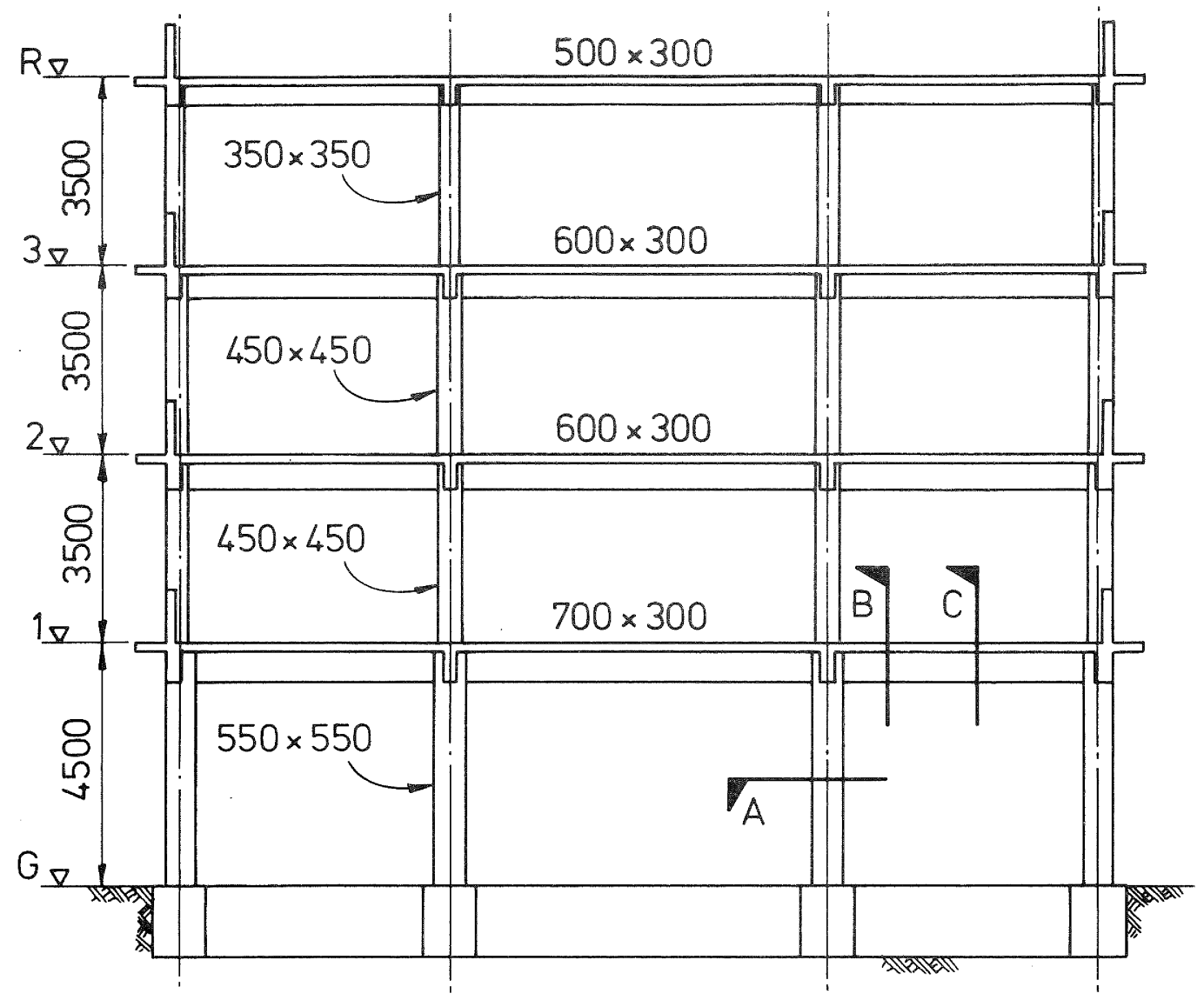

ELEVATION

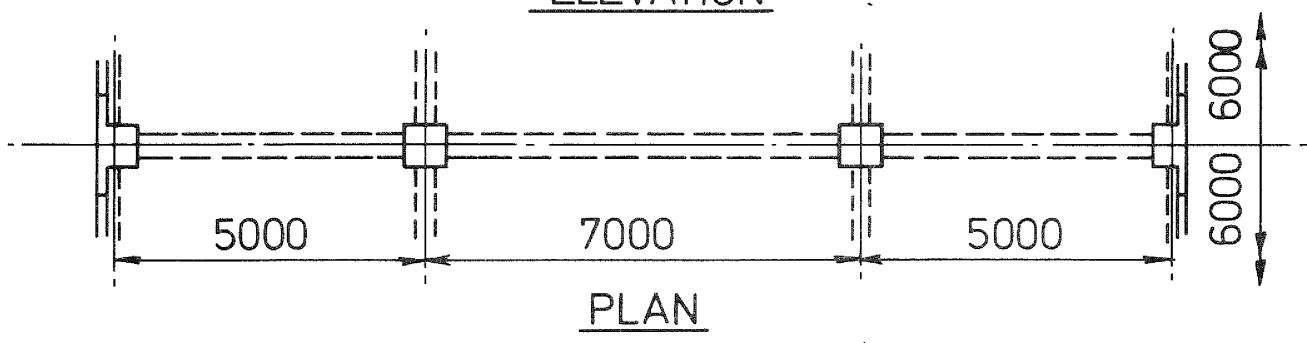

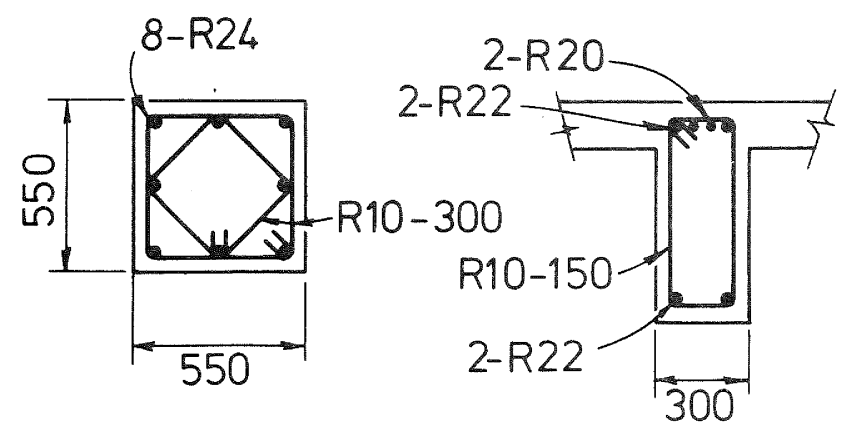

(A)

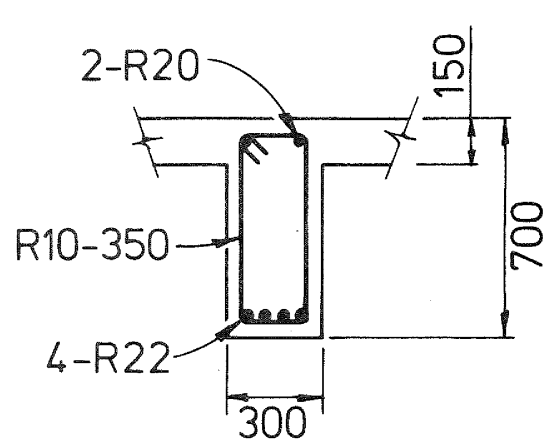

(C) 

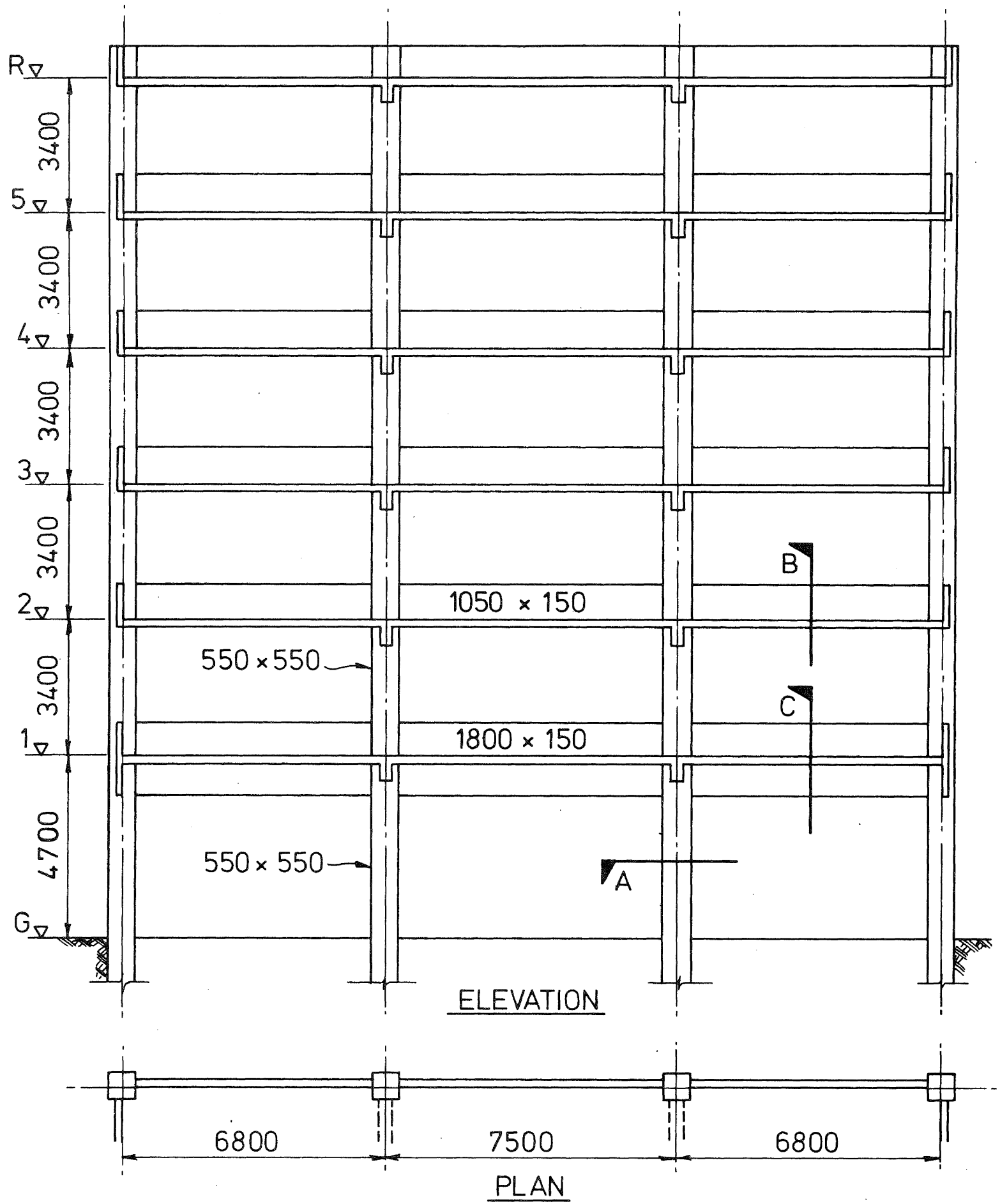

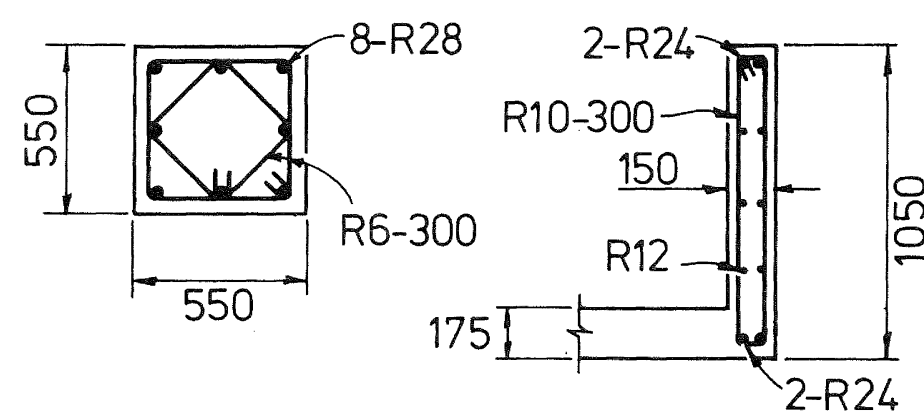

(A)

(B)

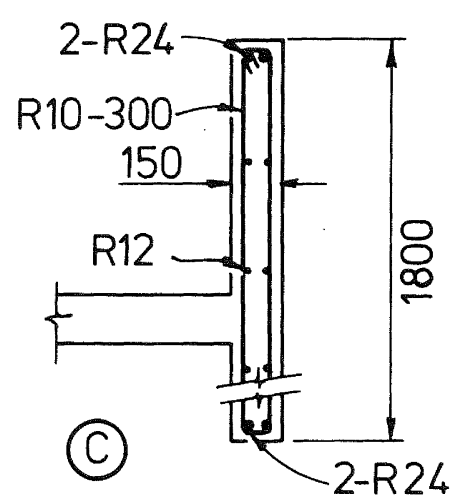

Figure 4 Details of Exterior Frame 
carried out to determine $\mathrm{P}_{\mathrm{eg}}$. The extreme earthquake-induced axial Idad $\mathrm{P}_{\text {eq }}^{\circ}$ can be determined from

$$
\mathrm{P}_{\text {eq }}^{\circ}=\lambda \mathrm{P}_{\text {eq }}
$$

where $\lambda=\frac{V_{\text {oe }}}{\mathrm{V}_{\text {code }}}$

in which $\mathrm{V}_{\mathrm{oe}}=$ shear demand associated with the development of flexural overstrength in beams $\mathrm{V}_{\text {code }}=$ shear force obtained from
the frame analysis.

The factor $\lambda$ is approximate in nature, as it requires averaging of values obtained for each beam in each direction, and is based on the assumption that full beam overstrengths can develop. It is advocated that $\lambda$ be based on first floor parameters only, in order to simplify the computational process.

Using a value of $1.5 \mathrm{f}$ ' in the sample calculation of column flexural capacity generated an increase of between 5 and 13 percent, depending on the level of axial load used.

\section{Column Shear}

Evaluation of column shear capacities, as for column flexural capacities, depends on an initial estimation of the level of axial load. Values of $P$ obtained for the determination of column flexural capacities may also be used in shear calculations.

As for beams, there are two levels of concrete shear contribution defined in NZS 3101 for columns. Code equation (7-41) allows a concrete contribution in the end region of seismic columns of

$v_{c}=4 v_{b} \sqrt{\frac{P_{e}}{A_{g^{f}}}-0.1}$

Code Eq $(7-41)$

As this equation implies, and the accompanying clause 7.5 .2 .2 states, $v$ shall be taken as zero if the axial force $P$ produces an average compressive stress less than $0.1 \mathrm{f}^{\prime}$. Non-ductile columns have a maximum concrete shear contribution

$$
v_{c}=\left[1+\frac{3 P_{u}}{A_{g} f_{c}^{\prime}}\right] v_{b}
$$

Code Eq (7-5)

For the reasons outlined above in the section on beam shear, the latter equation is considered to produce the more suitable value for initial strength evaluation purposes.

Use of higher concrete strength values in the evaluation of column shear capacities according to the non-ductile criteria above produces increases comparable to those observed for column flexural capacities. This similarity in increase between the two modes indicates that the actual value of $f_{C}^{\prime}$ used in the analysis will not influence the failure mode finally obtained.

However, in estimating the ductile shear capacity of columns the presence of the term A E in code equation (7-41) leads to a on in $v$ with increasing $f^{\prime}$ values. This remlt ${ }^{c}$ is inconsistent with conventional approaches for concrete shear capacity.

\section{Joints}

As discussed previously, the joints of nany early frames feature little or no joint reinforcing (refer Figure 2), and hence may be expected to perform poorly under earthquake loading conditions. It is possible to apply the design provisions of Chapter Nine of NZS 3101 in order to evaluate the shear capacity of existing joints, as described elsewhere ${ }^{8}$. However, there are shortcomings associated with this approach, and these can be summarised as:

1) Tha joint design provisions of NZS 3101 witn respect to the capacity of the joint concrete are very conservative where only limited ductility of adjacent plastic hinges occurs.

2) In order to determine the forces acting upon a joint, the assumption that either both adjacent beams or columns are yielding in flexure must be made. This is clearly unrealistic for the case of column hinging in particular.

3) The results can only be readily expressed as a percentage of the adjacent member force (at yield), which in turn cannot be easily related to the level of lateral load applied to the frame.

O. perhaps greater importance is that the joint shear capacity equations in the code give no quantitative indication of the bond performance of the joint. Bond conditions are likely to be critical in many joints, given the poor standard of detailing and the use of non-deformed main bars. As an example of this, clause 5.5.2.5(b) of NZS 3101 restricts the diameter of beam bars passing through interior joints according to the ratio

$$
\frac{\mathrm{d}_{\mathrm{b}}}{\mathrm{h}_{\mathrm{c}}} \leq \frac{1}{25}
$$

for Grade 275 reinforcement. The interior joints of the frame represented in Figure 3 as shown earlier in r'igure $2 a$, only just satisfy this ratio, but contain nondeformed beam bars, which are not permitted by NZS 3101. Premature bar slip through the joint core in this and other frames may thus be expected, but information on the ultimate bond stress, and the rate at which this degrades with cycling, are not available.

\section{INELASTIC ANALYSIS OF SAMPLE FRAMES}

In order to investigate further the typical characteristics of structures designed 
to earlier seismic codes, the drawings and specifications of two existing reinforced concrete buildings constructed in the mid-1950s were obtained, and from each of these a single frame was extracted. The inelastic performance of these frames was investigated using the two-dimensional time-history program "Ruaumoko", developed by sharpe, and subsequently modified by Carr $(197)$

The details of the two frames, one interior and one exterior, are shown in Figures 3 and 4. Both frames were chosen to be of unequal span configuration to avoid any symmetrical or balancing effects associated with single- or double-bay equal span structures. It can be seen that the exterior frame features deep spandrel beams, in addition to having constant member sizes above the first floor.

\section{Program Input}

Input consisted of member stiffnesses and probable flexural strengths based on details from the original drawings. The originally specified $f^{\prime}$ and $f$ values were used in the evaluation $Y$ of member strengths. Allowance for reduction of member stiffness with cracking was made by specifying shear and flexural stiffnesses based on $0.5 \mathrm{~A}$ and $0.5 \mathrm{I}$ for the beams and $0.8 \mathrm{~A}$ and $0.8 \mathrm{I}$ for the columns, where $A$ and ${ }^{9} I$ were the gross section area and moment ${ }^{g}$ of inertia respectively. Inelastic moment-curvature relationships were assumed to be bilinear with a strain hardening factor of 2 percent. Structure damping was represented by the use of the Rayleigh model, and lumped nodal weights were determined under the $\mathrm{D}+\mathrm{L} / 3$ load combination.

The frames were subjected to the El Centro N-S 1940 earthquake record only, as the NZS 4203 design spectra is based on Californian accelerograms scaled to El Centro magnitude. This programme was run initially with a scale factor of unity in order to represent a zone A earthquake, and then re-run subsequently for the Zone $B$ equivalent using a scale factor of 0.833 The modal analysis option of the programme revealed that the interior and exterior frames had fundamental periods of 0.75 and 0.67 seconds respectively.

The key problem encountered with this program related to the fact that failure in either the flexural or axial mode was assumed for the members, there being no provision for individual members failing in shear to be identified. This necessitated an additional manual investigation to see if any of the members had exceeded their shear capacities, with particular emphasis on members for which hinging action was indicated. This was a straight forward matter for the beams, but axialshear force interaction curves were required to carry out this check for the columns. The non-ductile shear capacity was used as the key parameter in this process, for the reasons described in the previous section.

\section{Results of Analysis}

The results obtained from the El Centro earthquake record indicated that appreciable inelastic activity could be expected in the members of both frames. In each case only the first ten seconds of the earthquake record was run and three and four response peaks were produced for the exterior and interior frames respectively. However, after applying the check for shear capacity as described above, it became apparent that the sample frames were unlikely to survive the entire record.

The response of the frames for the first peak in each direction of load is shown in Figure 5, for the frames assumed to be located in zone $\mathrm{A}$. In addition to the incidence of member shear failure, the most notable feature of these response peaks is the irregular hinge formation that occurs. However, despite the absence of a conventional beam or column hinging mechanism (apart from briefly in the case of the interior frame), considerable energy is still dissipated by the yielding regions. This is illustrated by the plots of base shear force vs roof level deflection for each frame shown in Figures $6 \mathrm{a}$ and $b$ for the first load peak.

Figure $5 \mathrm{a}$ shows that for the interior frame, the beam overstressed in shear on the second response peak is not the same as for the first, which implies that the structure is likely to survive until at least the second peak. The top soft storey flexural mechanism that forms for the case of $\vec{E}$ has an associated ductility demand of approximately four, and so this also may not represent a failure state. However, when the expected level of joint degradation is considered, the frame would probably not possess sufficient strength to withstand the subsequent major pulses of the El Centro record.

By contrast to the interior frame, the failure of the central columns of the exterior frame as shown in Figure 5b effectively represents a potential collapse state. The structure may survive until the second peak, for as Figure $6 \mathrm{~b}$ shows, the critical columns yield in shear only fractionally before the peak displacement is attained. But the same columns again yield in shear under $\vec{E}$, which in all probability would lead to a frame collapse.

Also of significance is the high level of lateral load at which member flexural yielding first occurs within the frames. As indicated by Figures $6 a$ and $b$, inelastic activity was first recorded at 44 percent and 47 percent of the zone $A$ code elastic design forces given by Equation 3. for the interior and exterior frame respectively. In contrast, fully ductile reinforced concrete frames designed to NZS 4203 (that is, $S=M=0.8$ ) are intended to yield in flexure at only 16 percent of code elastic levels.

A similar pattern of response was observed for both frames when subjected to a zone $B$ (scaled) version of this excitation, with fewer plastic hinges and slightly reduced deflections in evidence. 

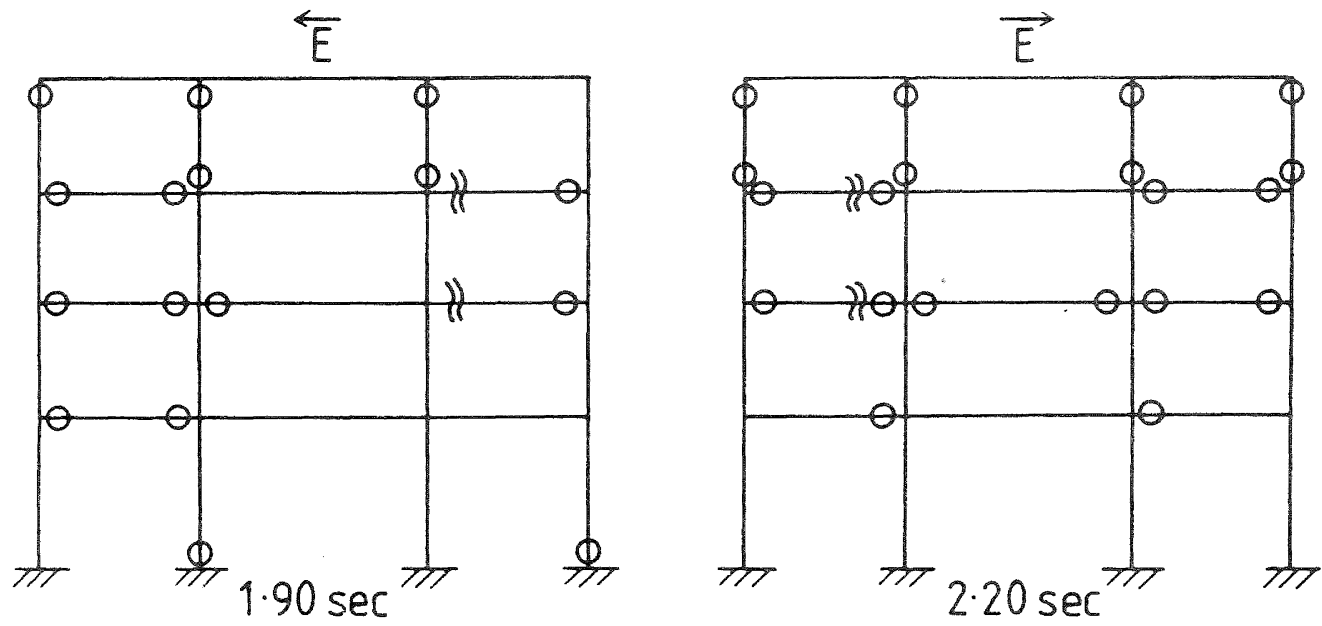

$0=$ Plastic hinge

$\approx=$ Yield in shear

(a) Interior Frame

$\overleftarrow{E}$

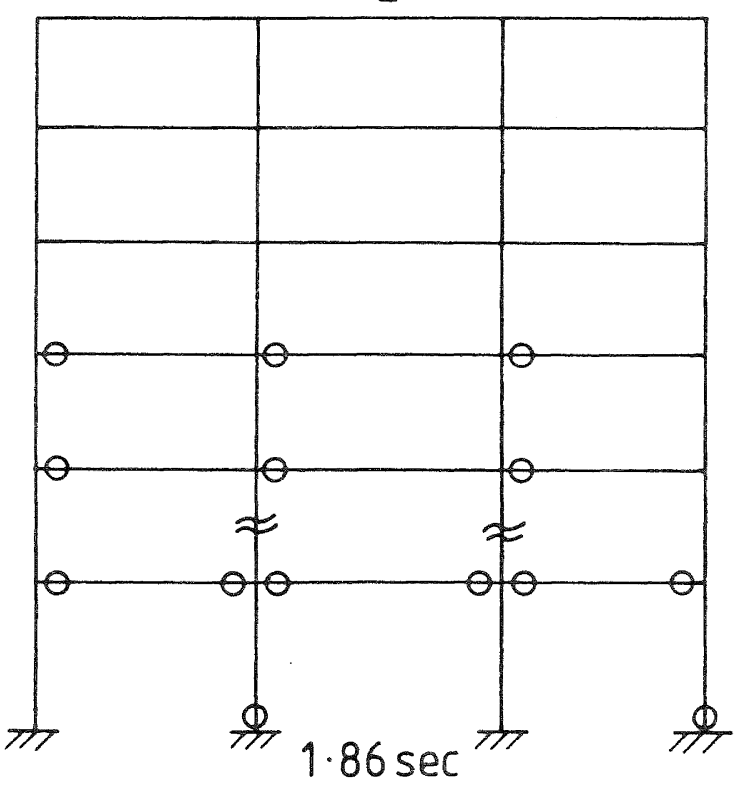

$\vec{E}$

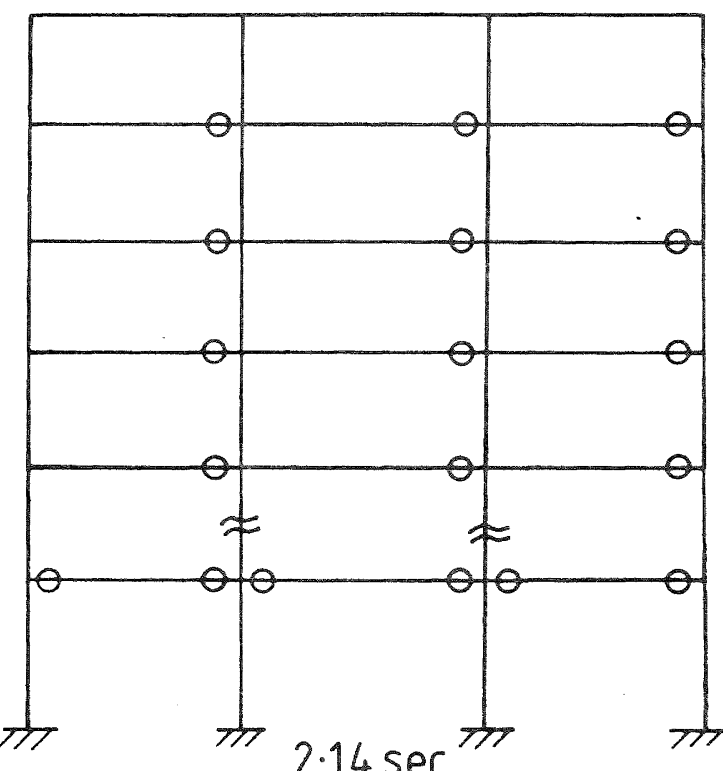

(b) Exterior Frame

Figure 5 Resporse of Frames to El Centro Record 


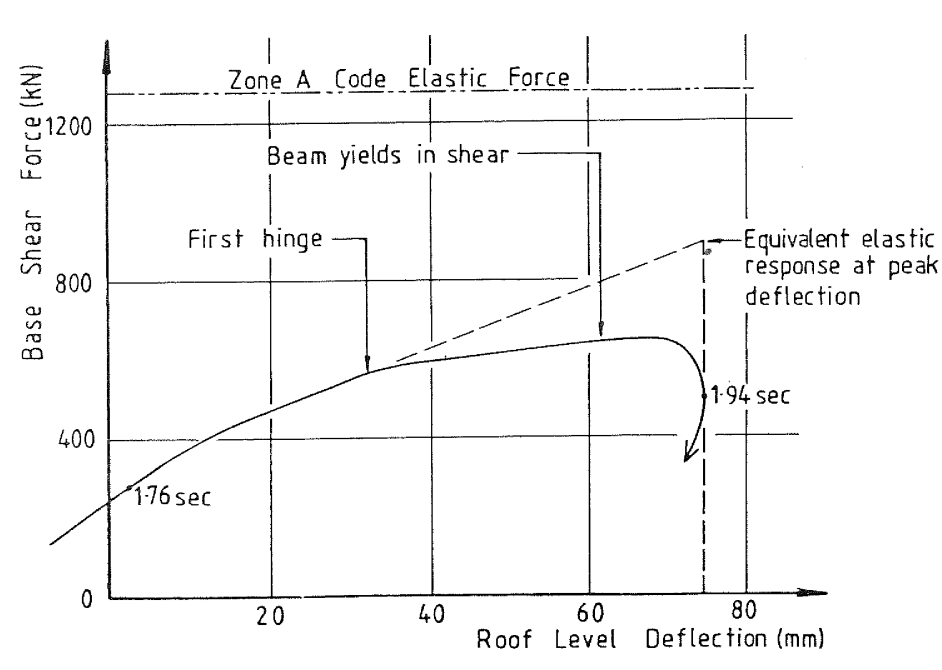

(a) Interior Frame

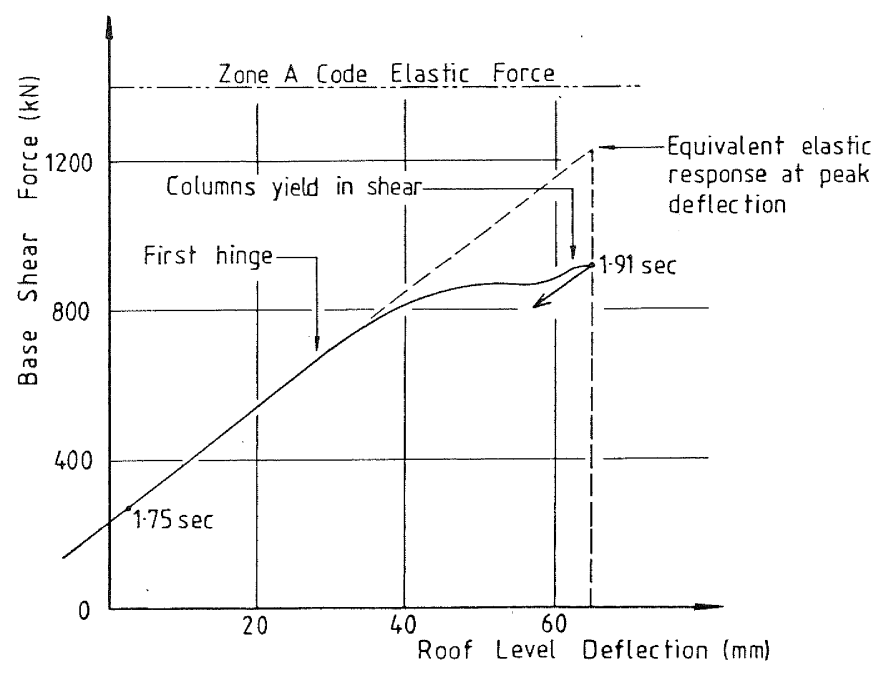

(b) Exterior Frame

Figure 6 Base Shear Force vs Roof Level Deflection Relationship

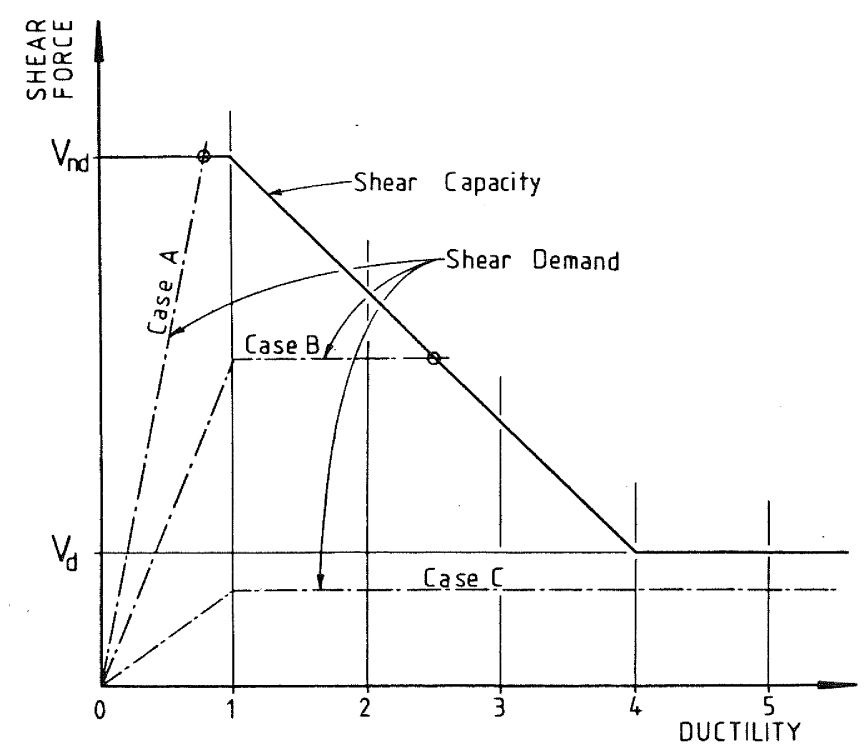

Case A: Beams or columns yielding in shear

Cases B\&C: Beams or columns yielding in flexure 
PROPOSED ASSESSMENT PROCEDURES FOR REINFORCED CONCRETE FRAMES

The capacity desjign procedures (fpntained within NZS $4203^{(3)}$ and NZS 3101 represent a deterministic design approach which produce only an upper bound performance criteria when applied to existing structures. Although any element satisfying the various ductile code requirements is virtually guaranteed to behave in a totally acceptable manner, failure to satisfy the design criteria will not necessarily lead to a catastrophic failure. Consequently, modifications for analysis purposes of some of the frame design requirements of NZS 3101 are applicable in developing a procedure for assessing the seismic performance of frame elements.

Rationalisation of NZS 3101 Design Procedures

In conjunction with the proposed frame analysis method described subsequently, the following departures from the NZS 3101 design provisions are suggested.

1) The Non-Use of the Dynamic Magnification Factor

The dynamic magnification factor $\omega$ is applied to the design shear forces and moments for columns in order to give a high degree of protection against premature yielding. The use of $\omega$ allows for the occurrence of bending moment patterns different from those elastically derived from the equivalent static load, with the intention of preventing column hinging occurring in a way that could promote the formation of a storey sway mechanism. Values of $\omega$ are contained in Table C3.A1 of the commentary to NZS 3101 .

After reviewing the research and theory behind the use of $\omega$, it was decided not to employ this factor in the assessment of frames for the following reasons:

i) Higher mode effects - current code provisions for simultaneous application of full overstrength of beam plastic hinges (which normally corresponds to a strong first mode response) with higher mode effects (such as the $w$ factor for column design) are seen as unnecessarily conservative. Further, most buildings constructed in the period of concern are not sufficiently high to suffer from significant higher mode effects.

ii) Significance of column yielding - total protection against the formation of column hinges is desirable, but not essential. Even unconfined column hinges will have some ductility capacity (research at the University of Canterbury would support a displacement ductility capacity of 2 for unconfined columns). It should be noted that simultaneous yielding at top and bottom of all columns in a storey, which is unlikely to occur from a shift in moment patterns at a joint, is required to form a soft storey mechanism. Until this occurs, column displacement ductilities are unlikely to approach $\mu=2$.

2) The Non-Use of the Strength Reduction Factor $(\phi)$

The purpose of applying the strength reduction factor $\phi$ in the ultimate design of new structures is to account for uncertainties in computation, variations in materials strengths, and construction tolerances. Dependable flexural strength is conservative when evaluating the capacity of existing elements, particularly for columns, due to strength gains by concrete over the current lifespan of the structure. It is considered more realistic to use ideal strengths for shear capacities and probable strengths for maximum flexural capacities, where probable strength $=1.15 \mathrm{x}$ (Ideal strength). Probable strength is felt to be more appropriate than overstrength (1.25 x Ideal strength), for it appears that the member ductilities required to develop overstrengths are unlikely to develop. It may appear non-conservative to compare beam and column capacities at the same strength levels, but was considered reasonable in view of the beneficial effect of higher concrete strength on column capacities as discussed previously.

3) The Use of a Model for Post-Elastic Member Shear Behaviour

The earlier discussion on the evaluation of individual member shear capacities indicated that the non-ductile (non-seismic) code shear provisions produced the more realistic values for assessing the mode of member failure. However, if one is seeking to estimate the level of performance in the mode so obtained, account must be taken of the inevitable degradation of the concrete shear resisting mechanism once yield in either shear or flexure has occurred.

A model for the post-elastic shear behaviour of frame members is shown in Figure 7. This relationship relates the decrease from the non-ductile $(V)$ to the ductile $\left(V_{d}\right)$ shear capacity to member displacement ductility, and is a modified version of that proposed py the Applied Technology Council This model can be used as a shear failure criterion by determining the level of shear demand at the development of flexural yield at both ends of a member. The demand curves, as depicted by the case A, $B$ and $C$ lines in Figure 7 , represent the load history of the member, with failure assumed to occur when the demand line intersects the capacity curve. Essentially the model implies no available ductility for members yielding in shear (Case A), and although the "instant" failure is some- 
what unrealistic, particularly for beams, it is adopted in order to retain the mathematical simplicity of the model.

For Case B (flexural ductility limited by shear failure), the available ductility defined by the line of degradation linking $V_{n d}$ and $V_{d}$ is determined from the relationship

$$
\mu=1+\frac{3\left(v_{n d}-v_{d e m}\right)}{\left(V_{n d}-v_{d}\right)}
$$

in which $\mathrm{V}_{\text {m }}=$ the sum of the shear force associated with the development of flexural yield at both ends of a member and gravity shear force $(D+L / 3)$

and

$\mathrm{V}_{\text {nd' }} \mathrm{V}_{\mathrm{d}}$ are as defined previously. For Case $\mathrm{C}\left(\mathrm{V}_{\mathrm{C}}>\mathrm{V}_{\text {dem }}\right)$, a maximum displacement ductility of $\mu=4$ is suggested, as it is considered that neither members nor joints are sufficiently well detailed to withstand ductility demands in excess of this.

\section{PROPOSED FRAME ANALYSIS METHODOLOGY}

A modified version of the Applied Technology Council procedure for evaluating the seismic capacity of highway bridges $(12)$ is proposed for assessing the seismic performance of reinforced concrete frames. Essentially this method involves obtaining the member yield (capacity) properties from the construction details, and also the code (3) earthquake-induced (demand) forces from a frame analysis using the equivalent elastic response level, that is, $\mathrm{SM}=4.0$. The corresponding capacity and demand values for each mode at each location are expressed as a ratio, and consideration of the relative magnitudes of these ratios identifies the critical member, mode and level at which first yield may be expected.

The methodology is listed below. Where additional comment is considered necessary this is denoted [ ], and the comments are included following the methodology, along with two case studies which illustrate aspects of the procedure.

\section{1) Analysis of Structure as a Whole}

Step 1: Equivalent static Force Analysis

Obtain storey shear forces

Step 2: Overall Elastic and Torsional Analyses

Determine the distribution of storey shear force between lateral load resisting elements.

Perform separate torsional analysis (if not included as a part of the elastic analysis) to determine whether elastic forces need to be factored up.

2) Demand Values

Step 3: Elastic Analysis of the Frame

Either manually using a Muto procedure or a plane-frame computer program, apply the lateral forces indicated from step 2. The result is the individual member "code demand" forces (beam and column flexure and shear) corresponding, to a fully elastic response ${ }^{11}$.

This analysis also yields the column earthquake induced axial loads ( $\left.\mathrm{P}^{\circ}\right)$ which are subsequently used in conjunction with the results of the gravity analysis in the determination of column flexural and shear capacities $[2]$

\section{3) Capacity Values}

Step 4: Gravity Load Analysis

A conventional gravity load analysis of the frame is required to determine:

a) the column gravity axial loads $\left(D+I_{R}\right)$

b) the beam gravity load moments at the column faces $(D+\mathrm{L} / 3)$

c) the beam gravity load shear forces at a distance 'd' out from the support faces $\left(\mathrm{D}+\mathrm{L} / \mathrm{H}_{3}\right)$

Assemble the total earthquake axial load using the load case $P_{e}=P_{D}+P_{L R} \pm P_{\text {eq }}^{\circ}$ for each column

Step 5: Beam Earthquake Flexural Capacities

a) Evaluate beam positive and negative probable flexural strengths at the column faces (extrapolate to column centrelines if demand moments are at the centrelines), including allowance for slab reinforcing as appropriate.

b) Add/subtract gravity load moments in order to obtain 'true' earthquake flexural capacities for each direction of loading.

Step 6: Beam Earthquake Shear Capacities

a) Evaluate beam ideal nonductile shear capacities adjacent to the column.

b) Subtract gravity load shear forces in order to obtain 'true' earthquake shear capacities. 
Step 7: Column Flexural Capacities

Determine the probable flexural strengths for eagh

Step 8: Column Shear Capacities

Using equations (7-3) and (7-5) of NZS 3101, determine the ideal non-ductile shear capacities for each storey of each column.

4) Capacity/Demand Ratios

\section{Step 9: Elastic C/D Ratios}

Obtain the Capacity/Demand (C/D) ratios from the corresponding capacity and demand values and present in a form similar to that 4 shown in Figures 9 and $14^{[4]}$.

A C/D ratio of 0.5 , for example, indicates that yield in that mode at that location is likely to occur at one-half of the code elastic response level, or, put another way, under ground shaking of 50 percent the intensity of the design earthquake. This does not, however, necessarily constitute the maximum level of shaking that can be sustained, since ductility has not yet been considered.

\section{Step 10: Ductile C/D Ratios}

The steps involved in determining the ductile C/D ratios are summarised in Figure 8.

Apply the shear failure criterion of Figure 7 to members where applicable (that is, members for whom both elastic flexural C/D ratios are less than the shear C/D ratiol in order to estimate the available member ductility. The elastic flexural $C / D$ ratios are then multiplied by this ductility to obtain the ductile flexural C/D ratios. This procedure is illustrated for the case of the interior frame (Case study I) in the Appendix.

Step 11: Joints

Comparison of the elastic $C / D$ ratios at each node of the frame will indicate the governing member action at the joints (that is, beam or column hinging). A separate joint analysis can then be carried out using the provisions of Chapter Nine of NZS 3101 for joints that are considered to be critical.

\section{COMMENTS ON THE PROCEDURE}

[1] This can be achieved by either applying the elastic coefficient [ $(S M)=4.0]$ at Step 1, or using the ductile coefficients $\left[(S M)_{0}=0.64\right]$ originally and factoring up the resulting member forces.

[2] This has the effect of artificially setting the earthquake axial load multiplier (refer Equation (9)) $\lambda=6.25$, which will be excessively conservative for structures which respond significantly below code elastic levels. A more accurate, but still simple, alternative is to determine the actual average value of $\lambda$ at first floor leve as described previously (noting that it may be dictated by shear rather than flexure), and use this throughout the structure.

[3] Although step 5 advocates the extraction of gravity load moments and shear forces from the beam capacities, it is not considered necessary to do this for the column capacities. This is because the influence of applied gravity loads has a far greater effect on the 'true' earthquake capacities for beams than columns.

[4] C/D ratios may need to be determined for each direction of loading if either the beam flexural reinforcing or the overall frame layout is unsymmetrical. In any event, it is important that the beam and column ratios are compared for the same direction of loading, otherwise a false relationship between the two is obtained.

\section{CASE STUDY I: ISOLATED INTERIOR FRAME}

The interior frame shown in Figure 3 was analysed using the Capacity Demand (C/D) ratio method, and the elastic ratios are shown in Figure 9 for the frame, assumed to be located in Zone $\mathrm{B}$.

The manner in which the elastic $\mathrm{C} / \mathrm{D}$ ratios represent the sequence of actions can be illustrated by looking at the second floor beam $A B$. The ratios indicate that the left-hand end will yield in flexure at approximately 44 percent of the full code elastic response level, with the righthand end yielding at 53 percent. The shear ratio implies that if flexural yield had not occurred, the beam would yield in shear at 54 percent of the code elastic level.

The shear failure criterion of Figure 7 can then be applied to this member to estimate the available displacement ductility. and sample calculations for this stage of the procedure are included in the Appendix. Ductile C/D ratios less than one are shown in Figure 10 for members of the frame where applicable.

The ductile C/D ratios in Figure 10 clearly identify critical members which is especially useful in cases where strengthening work is being contemplated. A pictorial representation of the frame at the nominal failure level predicted by Figure 10 (that 


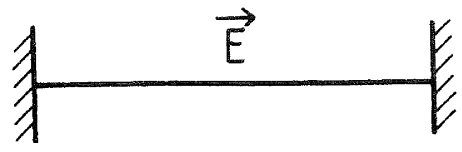

Elastic C/D Ratios

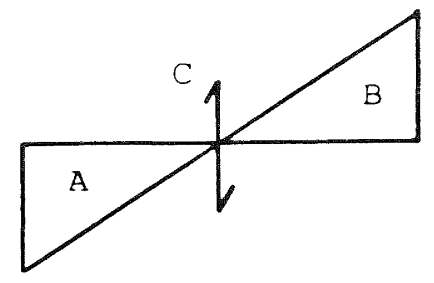
$A, B=$ elastic flexural C/D ratios
$\mathrm{C}=$ shear $\mathrm{C} / \mathrm{D}$ ratio

Estimate Member Ductilities Using Shear Failure Criterion (Fig. 7 )

Ductile C/D Ratios

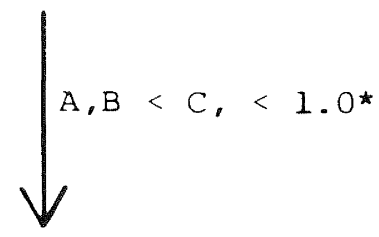

$\mu$
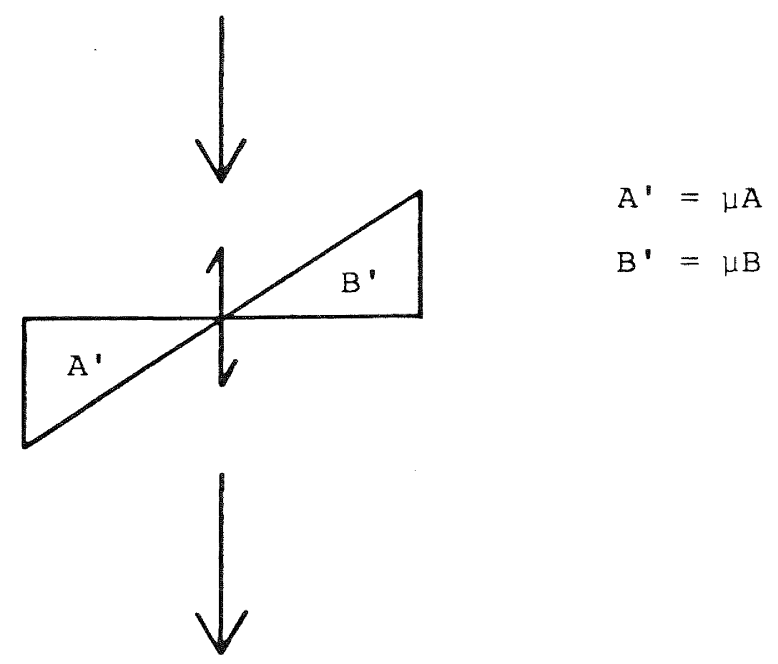

Member Failure Occurs

at the Level Corresponding

to the Lower of $A$ 'or $B$ '

*If $\mathrm{A}$ or $\mathrm{B}$ is greater than $\mathrm{C}$ then member failure is assumed to occur at the level corresponding to $\mathrm{C}$.

Figure 8 Summary of Procedure Once Elastic C/D Ratios Have been Determined 
is, 62 percent of the code elastic level) can be obtained by identifying elastic $C / D$ ratios with values less than this level, and is shown in Figure 11. It should be noted that this does not necessarily represent the collapse state of this frame, as it is likely that additional load can be taken by the frame before the critical beam fails catastrophically.

The manner in which this method aids in the investigation of joint capacity can be illustrated by considering the circled joint in Figure 9. By separately summing the beam and column elastic flexural ratios, one can see there is sufficient column strength $(\Sigma=1.60)$ to enable hinges at the end of adjacent beams to form $(\Sigma=1.36)$.

It would appear that this frame, which is capable of sustaining close to twothirds of current NZS 4203 design earthquake levels, might be considered acceptable.

\section{CASE STUDY II: FRAME-WALL STRUCTURE}

The subject of this case study investigation is a nine storey office building constructed in 1958 and located in seismic zone A. The ground floor plan of this frame-wall structure is shown in Figure 12, and the details of the Type 3 exterior frame is shown in Figure 13.

The elastic analysis option of the programme described previously was used to determine the distribution of the equivalent static forces between elements in the transverse direction. A torsional analysis was carried out at the ground and fourth floor levels, and the centres of rigidity for both levels are shown in relation to the centre of mass in Figure 12. The substantial ground floor eccentricity is largely a result of the increase in storey height toward the Type 3 frame due to a fall in the ground floor level (see Figure 13). The lateral loads applied to the frames were factored up as appropriate to allow for the eccentricities, and this led to a substantial increase in the case of the Type 3 frame loads.

The Types 1 and 3 frames were analysed using the Capacity/Demand ratio approach, and the results are shown in Figures 14 and 15 for the case of $\vec{E}$. The behaviour of the frames and the main wall element is briefly reviewed here, with a morf, detailed description available elsewhere ${ }^{(8)}$

\section{Type 1 Frame}

This frame appears likely to perform reasonably well in the event of a zone A codelevel earthquake, with yielding in shear of the first floor beam $A B$ limiting the response of the frame. At the level at which this member yields in shear there are not likely to be significant inelastic actions elsewhere in the frame, and this is especially noticeable in the case of columns. The elastic $C / D$ ratios only are shown in Figure 14 , as the ductile ratio values are all appreciably in excess of one. Due to the lack of symmetry, this frame was also analysed for the case of $\mathrm{E}$, with similar results being obtained.

\section{Type 3 Frame}

The elastic C/D ratios in Figure 15 indicate that this frame is likely to fail at a very low level of lateral load as a result of shear failure of the columns between first and second floor level. With three out of the four columns yielding in shear, this effectively represents a potential collapse state. Since nonductile column shear capacity governs the response of this frame at very low levels of ground shaking, it was not considered relevant to evaluate the ductile C/D ratios.

\section{Wall}

This wall features boundary elements that act as columns for earthquake loading in the longitudinal direction, and these are heavily reinforced. A brief analysis of the wall revealed that the web possesses insufficient shear capacity to enable flexural yield to occur. Taking account of the torsionally-induced forces, this wall appears likely to fail in shear at approximately 40 percent of the code elastic response level.

It is clear that the performance of the structure as a whole will be heavily influenced by the poor performance of the Type 3 frame. This unsatisfactory behaviour is a consequence of both the geometry of the exterior frame, which features deep spandrel beams, and its eccentric location with respect to the centre of rigidity. This structure would clearly qualify for strengthening measures.

\section{CONCLUSIONS}

Comparison of the design levels for seismic lateral loads of NZSS 95 and NZSS 1900 with NZS 4203 indicated that buildings constructed between 1935 and 1975 are likely to be substandard in the light of current seismic performance criteria. The shortfall in performance cannot easily be determined because it depends on the ductility capacity and mode of failure of the structure.

Case studies of a number of buildings constructed between 1935 and 1975 clearly indicated that simple "broad-brush" evaluations of existing buildings will rarely be successful. This is a consequence of the complex modes of inelastic behaviour that are likely to develop, with beam hinges, column hinges and shear failures likely to develop at different locations within the frames.

An assessment methodology, described in this paper, is felt to provide a reasonable approach to determining the seismic capacity of a building. It allows relaxation of many of the capacity design requirements of the Loadings Code NZS 4203, and the Concrete Design Code NZS 3101, and 


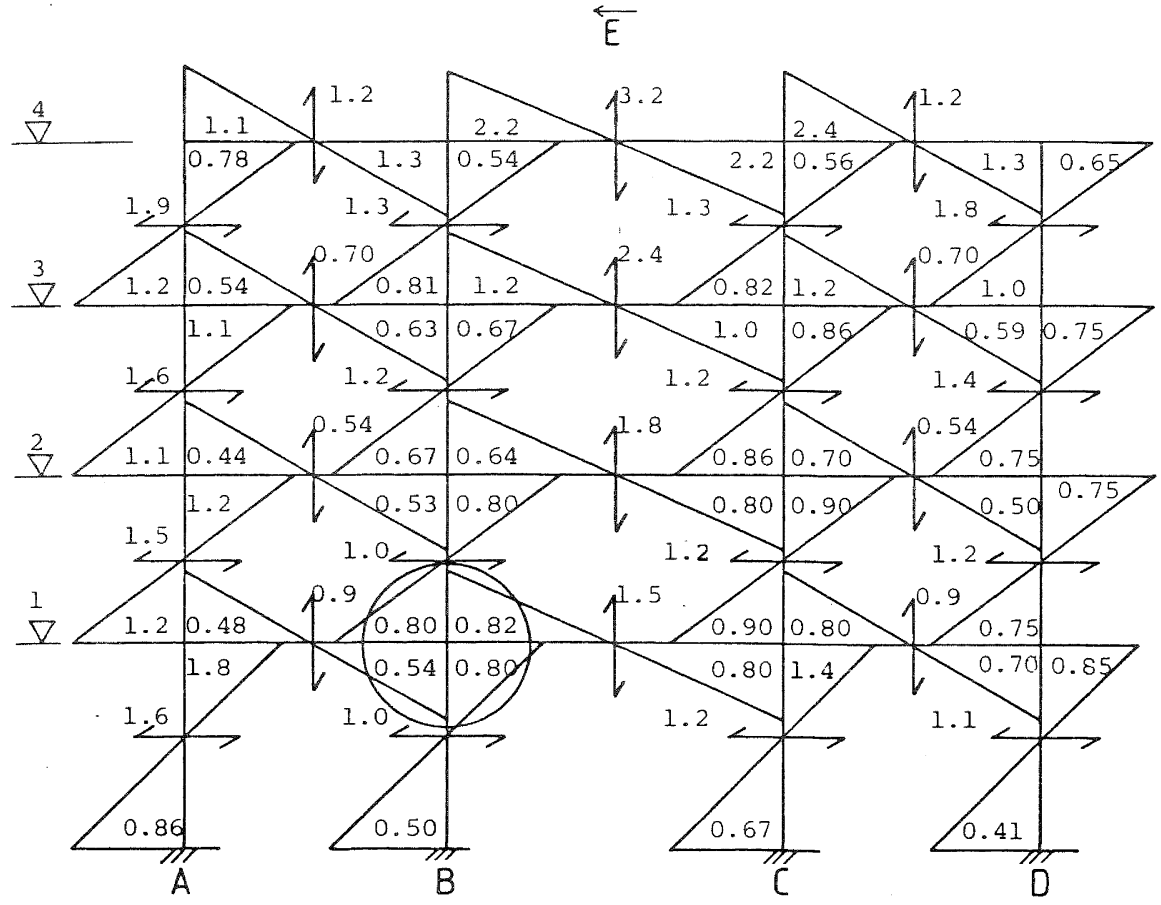

Figure 9

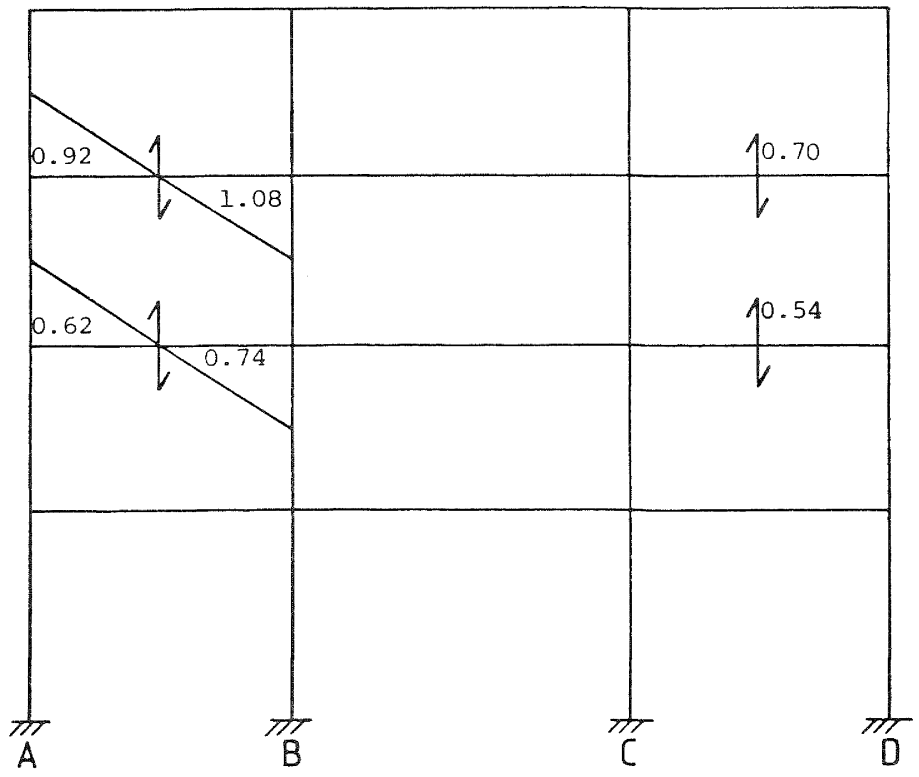




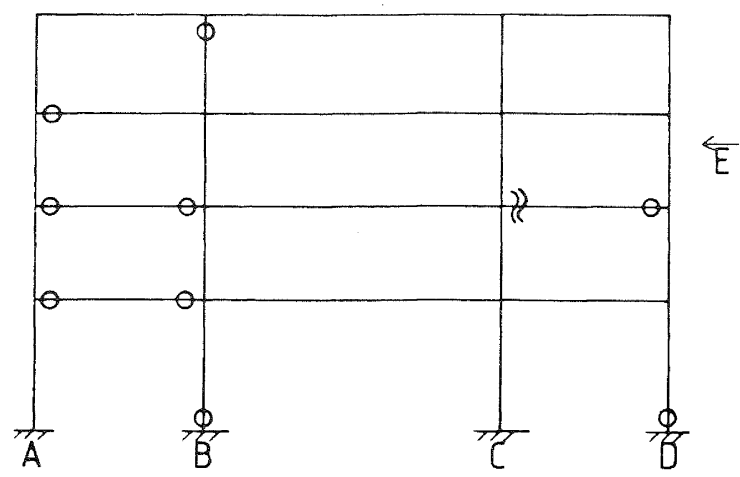

Figure 11 Yield State of Interior Frame at Nominal Failure Level

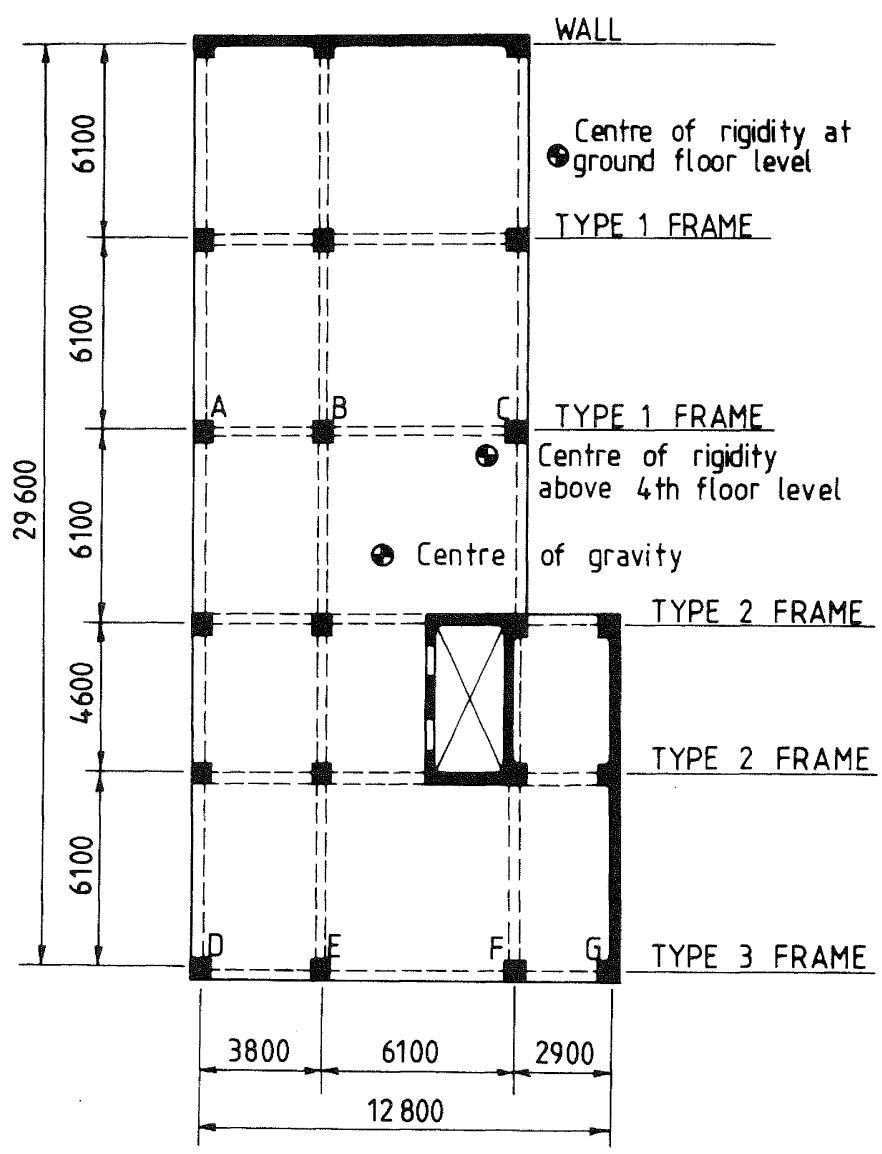


includes a model for the degradation of shear strength with ductility. This is felt to be essential in assessing the ductility of plastic hinges.

The most difficult aspect to assess quantitatively was found to be the shear strength and integrity of beam-column joints. Use of plain-bar for beam steel, and light, if any, joint reinforcement, is likely to limit flexural capacity and ductility of adjacent hinges. Some testing is urgently required to provide information about the strength and rate of degradation of such joints.

\section{ACKNOWLEDGEMENTS}

The financial assistance of the Ministry of Works and Development and the New Zealand Concrete Research Association is gratefully acknowledged, as is the assistance of the Wellington, Christchurch and Lower Hutt City Councils in making information available. The research on which this paper is based was part of a Master of Engineering project by $D$ R Brunsdon, supervised by M J N Priestley, at the University of Canterbury.

APPENDIX: ILLUSTRATION OF THE APPLICATION OF THE SHEAR FAILURE CRITERION

This appendix illustrates the application of the post-elastic shear failure behaviour model (represented in Figure 7) as used in the Capacity/Demand ratio method of analysis. A beam taken from the interior frame analysed in Case study $I$ is used for this example.

The location of the second floor beam $A B$ is indicated in Figure 9 , and the elastic C/D ratios are reproduced below:

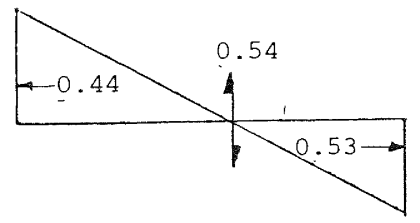

The relevant member capacities and shear demands are

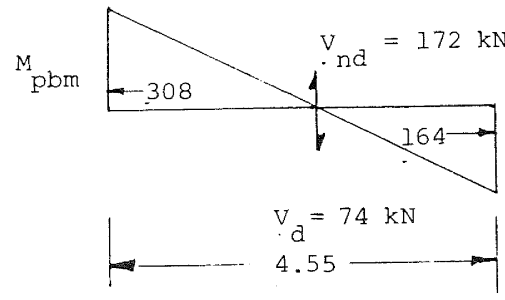

$\begin{aligned} \mathrm{V}_{\mathrm{pe}}=\frac{308+164}{4.55} & =103 \mathrm{kN} \\ \mathrm{V}_{\text {grav }} & =56 \mathrm{kN} \\ \mathrm{V}_{\text {dem }} & =159 \mathrm{kN}\end{aligned}$

Using equation (10):

$$
\begin{aligned}
\mu & =1+\frac{3\left(v_{n d}-V_{d e m}\right)}{V_{n d}-V_{d}} \\
& =1+\frac{3(172-159)}{(172-74)} \\
& =1.4
\end{aligned}
$$

The ductile flexural $C / D$ ratios can then be obtained as follows:

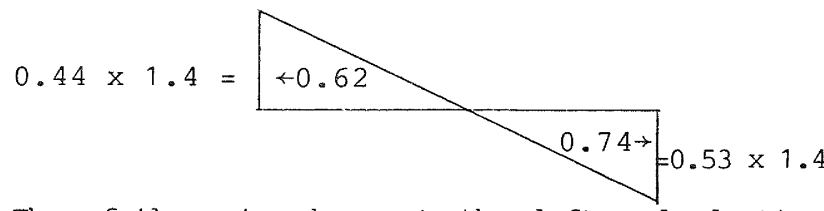

Thus failure in shear at the left end plastic hinge is expected at about 60 percent of the code level of ground shaking.

\section{NOTATION}

A

C member capacity OR basic seismic coefficient

$d_{b} \quad$ diameter of reinforcing bar

D dead load OR code demand

E earthquake load

$f^{\prime}$ specified concrete compressive stress

$f_{y} \quad$ specified yield stress of steel reinforcement

h overall depth of column in the direction of load

$I_{g}$

L

$\mathrm{L}_{\mathrm{R}}$

$\mathrm{M}$

gross section moment of inertia

live load, to NzS 4203

reduced live load, to NZS 4203

structural material factor used in derivation of the lateral force coefficient $\mathrm{C}_{\mathrm{d}}$

$M_{p} \quad$ probable strength flexural capacity

$\mathrm{P}_{\mathrm{D}}$ axial load on a column due to dead load only

$\mathrm{Pe}$ axial load due to gravity and seismic load acting on a column during an earthquake

$P_{\text {eq axial load on a column due to }}$ earthquake loading only

$\mathrm{P}_{\text {eq }}^{\circ}$ maximum axial load on a column due to earthquake only at the development of beam flexural overstrength

$P_{\text {I }}$ axial load on a column due to reduced live load

$\mathrm{P}_{\mathrm{u}} \quad$ ultimate axial load on a column

$S$ structural type factor used in the derivation of the lateral force coefficient $\mathrm{C}_{d}$

$\mathrm{T}$ fundamental period of vibration

$v_{b} \quad$ basic shear stress 


\begin{tabular}{|c|c|}
\hline $\mathrm{V}_{\mathrm{C}}$ & $\begin{array}{l}\text { permissible } \\
\text { by concrete }\end{array}$ \\
\hline$v_{i}$ & ideal shear stress $=\mathrm{v}_{\mathrm{C}}+\mathrm{V}_{\mathrm{s}}$ \\
\hline$V_{S}$ & $\begin{array}{l}\text { shear stress allocated to rein- } \\
\text { forcement }\end{array}$ \\
\hline$V_{\text {code }}$ & $\begin{array}{l}\text { shear demand derived from code } \\
\text { loading }\end{array}$ \\
\hline$V_{d}$ & $\begin{array}{l}\text { member shear capacity derived } \\
\text { from code ductile (seismic) cri- } \\
\text { teria }\end{array}$ \\
\hline$V_{\text {dem }}$ & $\begin{array}{l}\text { sum of flexurally-induced shear } \\
\text { force (V pe) and gravity shear } \\
\text { force (V grav) }\end{array}$ \\
\hline Vgrav & $\begin{array}{l}\text { shear force on member due to } \\
\text { realistic gravity load }(D+L / 3)\end{array}$ \\
\hline$V_{\text {nd }}$ & $\begin{array}{l}\text { member shear capacity derived } \\
\text { from code non-ductile (non-seismic) } \\
\text { criteria }\end{array}$ \\
\hline$V_{\text {oe }} \cdot V_{\text {pe }}$ & $\begin{array}{l}\text { shear force resulting from the } \\
\text { development of member flexural } \\
\text { overstrength and probable strength } \\
\text { respectively }\end{array}$ \\
\hline$\phi$ & strength reduction factor \\
\hline$\varepsilon_{C}$ & $\begin{array}{l}\text { specified compression strain at } \\
\text { extreme concrete fibre }\end{array}$ \\
\hline$\mu$ & member displacement ductility \\
\hline$\mu^{\prime}$ & $\begin{array}{l}\text { anticipated ductility capacity } \\
\text { for structures of early design }\end{array}$ \\
\hline$\omega$ & dynamic magnification factor \\
\hline$\rho_{W}$ & ratio of tensile reinforcement \\
\hline$\lambda$ & $\begin{array}{l}\text { ratio of beam overstrength shear } \\
\text { demand to code beam shear force } \\
\left(=V_{\text {oe }} / V_{\text {code }}\right)\end{array}$ \\
\hline
\end{tabular}

REFERENCES

1. "New Zealand Standard Model Building By-Law" NZSS 95, New Zealand Standards Institute, Wellington, December $1935,94 \mathrm{pp}$.

2. "Basic Design Loads", Chapter 8, NZSS 1900, New Zealand Standards Institute, Wellington, December 1965, 39 pp.

3. "Code of Practice for General structural Design and Design Loadings for Buildings", NZS 4203, Standards Association of New Zealand, Wellington, $1976,80 \mathrm{pp}$.

4. Phillips, M H, "Destructive Testing of the Barkers Bridge", Report under preparation, Central Laboratories, Ministry of Works and Development, New Zealand.

5. Wright, P D, "Destructive Testing of the Karaka Creek Bridge", Central Laboratories, Ministry of Works and Development, New Zealand, Report No 5-81/11, June 1982 .

6. Fullarton, D H and Edmonds, F D, "Destructive Testing of the Mangataweka Stream Bridge", Central Laboratories, Ministry of Works and Development, New Zealand, Report No 5-78/1, April 1978.
7. "Code of Practice for the Design of Concrete Structures", NZS 3101, Standards Association of New Zealand, Wellington, $1982,283 \mathrm{pp}$.

8. Brunsdon, D R, "Seismic Performance Characteristics of Buildings Constructed Between 1936 and 1975", Master of Engineering Report, University of Canterbury, 1984, 208 pp.

9. Jury, R D, "Seismic Load Demands on Columns of Reinforced Concrete Multistorey Frames", Master of Engineering Report, University of Canterbury, $1978,129 \mathrm{pp}$.

10. Sharpe, R D, "The Seismic Response of Inelastic structures", PhD Thesis, University of Canterbury, Christchurch New Zealand, November 1974, 188 pp.

11. Sharpe, R D and Carr, A J, "Inelastic Frame Dynamic Analysis", Computer Program Library, Department of Civil Engineering, University of Canterbury, $1979,17 \mathrm{pp}$.

12. "Seismic Retrofitting Guidelines for Highway Bridges", Draft Report, Applied Technology Council, Committee ATC-6-2, Palo Alto, California, 1983. 


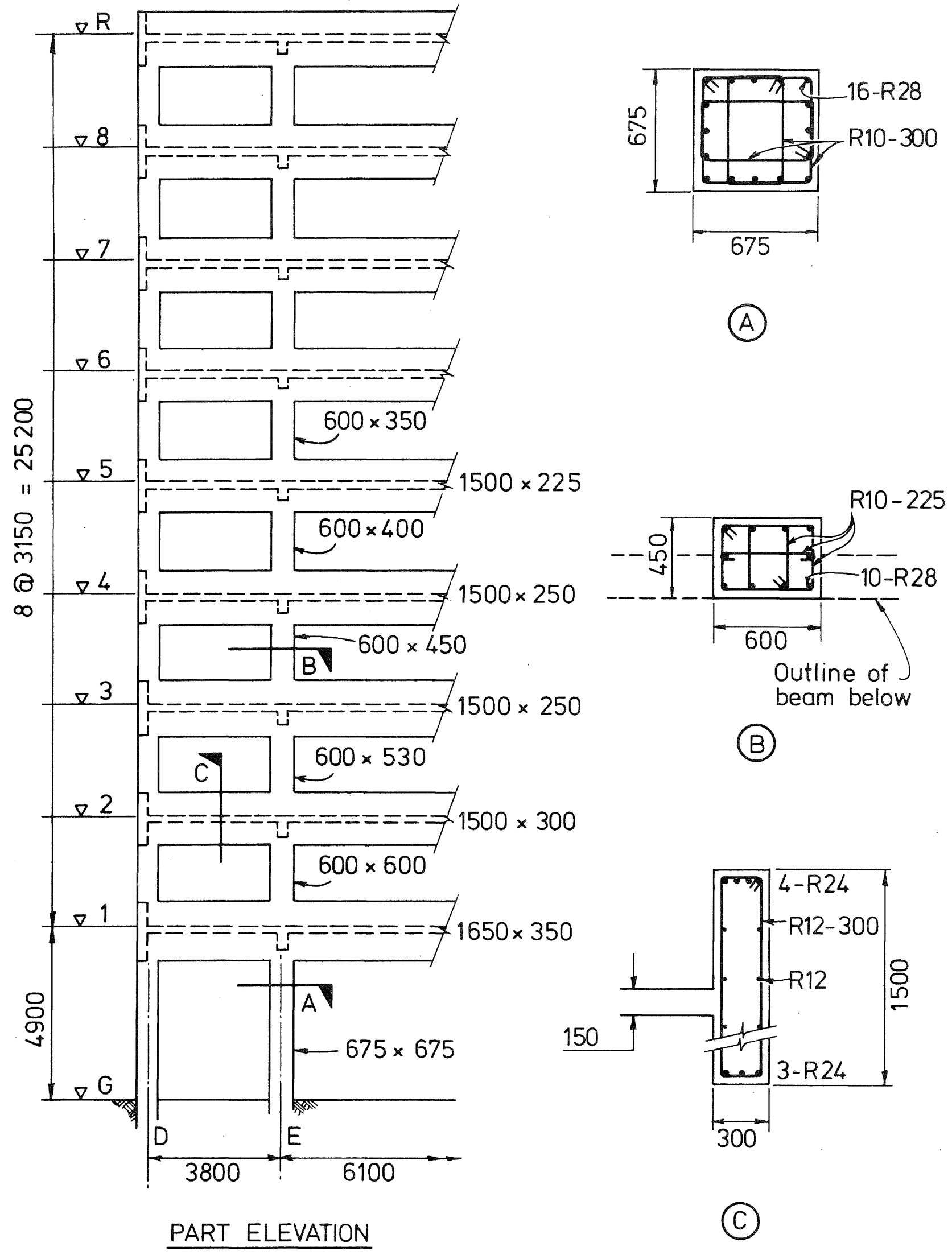




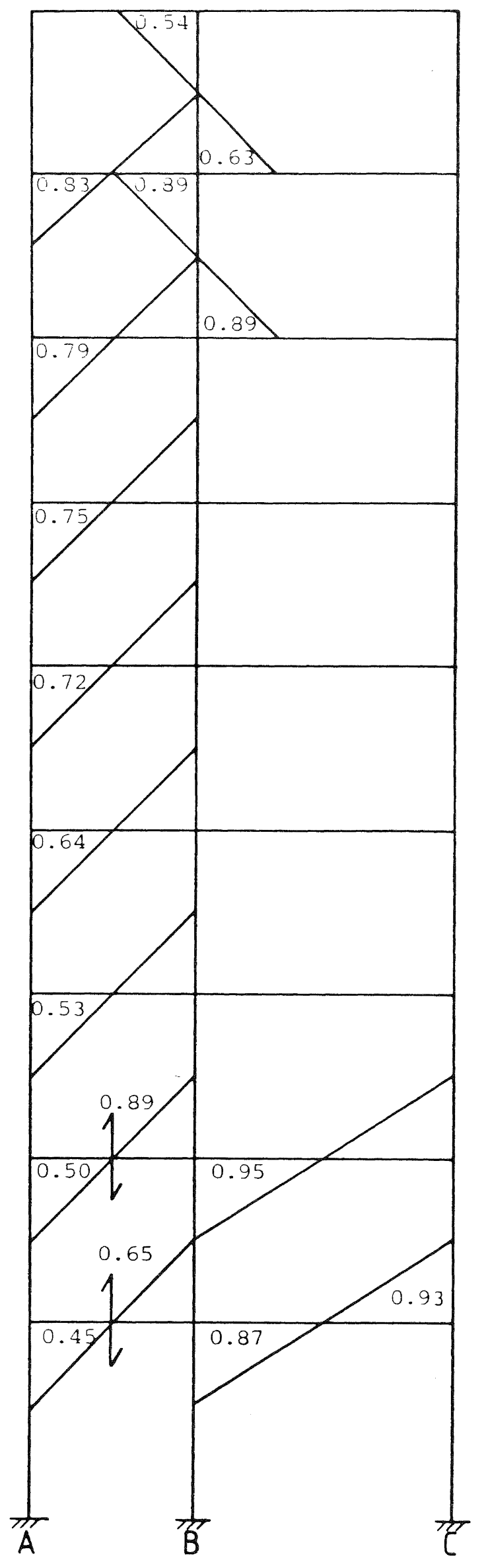

Figure 14 Results of Capacity/Demand Ratio Analysis of Type 1 Frame $(\vec{E})$ 
TABLE 1

MATERIAL PROPERTIES FROM THREE REINFORCED CONCRETE BRIDGES

CONSTRUCTED BETWEEN 1933 AND 1940

\begin{tabular}{|c|c|c|}
\hline & Steel Stress (MPa) & Concrete Stress (MPa) \\
\hline Originally Specified & $f_{y}=207$ & $f_{C}^{\prime}=17$ \\
\hline \multicolumn{3}{|l|}{ Results from testing } \\
\hline Barkers Bridge $(4)$ & $\begin{array}{l}\mathrm{f}_{\mathrm{y}}=276 \\
\mathrm{f}_{\mathrm{u}}=455\end{array}$ & $f_{C}^{\prime}=47$ \\
\hline Karaka Creek Bridge ${ }^{(5)}$ & $\begin{array}{l}f_{y}=310 \\
f_{u}=500\end{array}$ & $f_{C}^{\prime}=54$ \\
\hline Mangateweka Bridge ${ }^{(6)}$ & $\begin{array}{l}f_{y}=313 \\
f_{u}=515\end{array}$ & $f_{c}^{\prime}=50$ \\
\hline
\end{tabular}

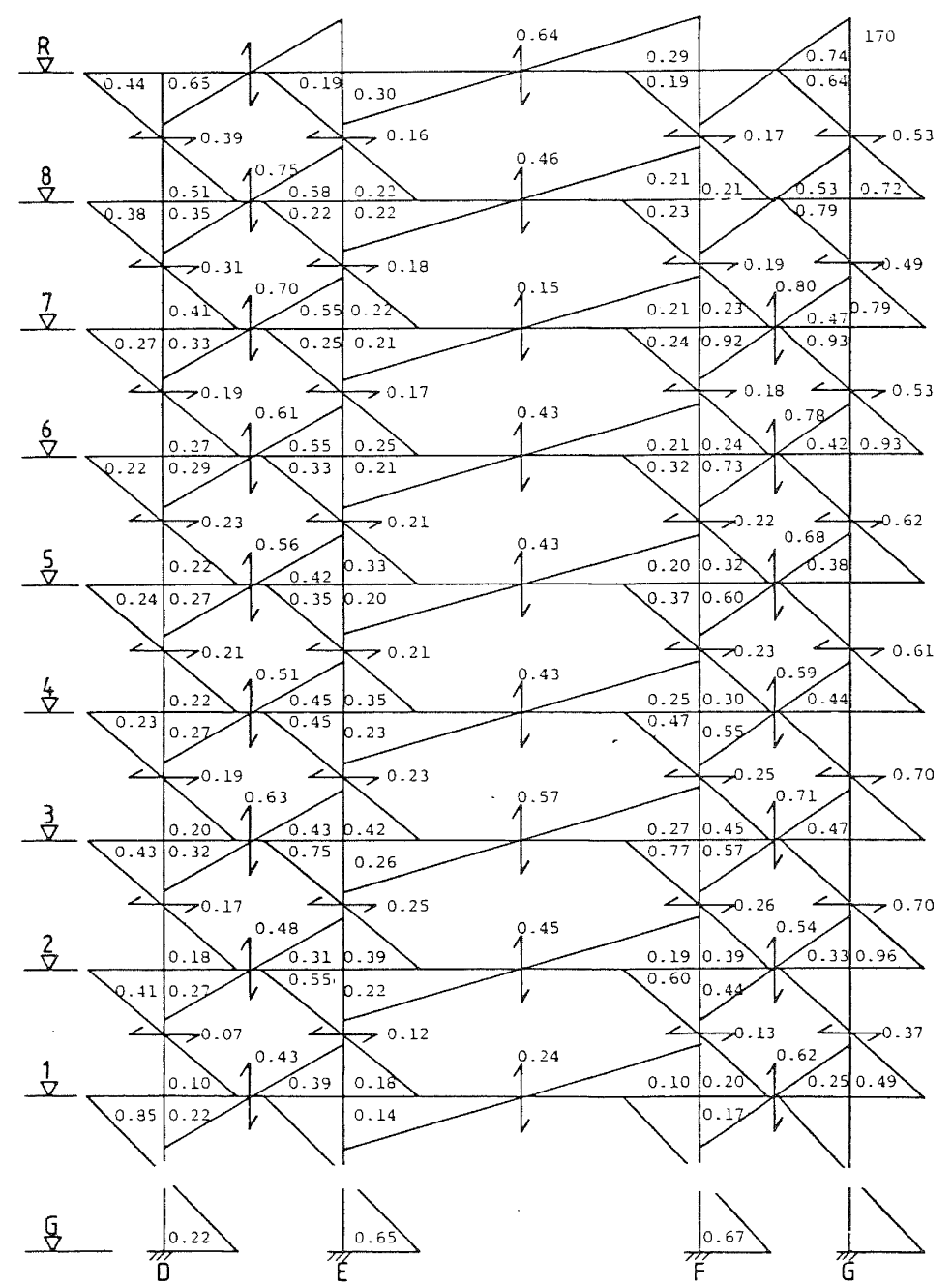

Figure 15 Results of Capacity/Demand Ratio Analysis of Type 3 Frame $(\vec{E})$ 